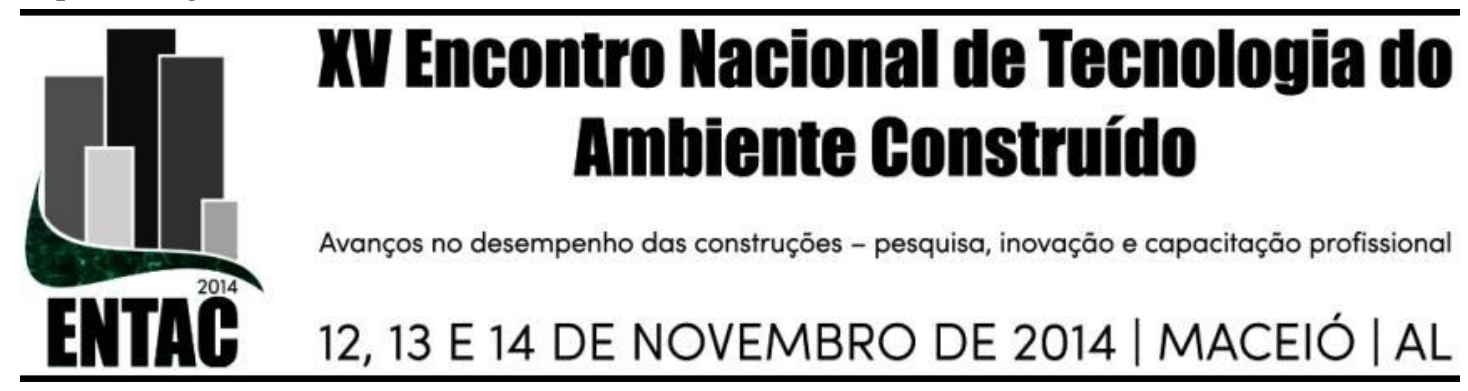

\title{
USO ADAPTADO DE ANDON EM UM EMPREENDIMENTO HORIZONTAL
}

\author{
BIOTTO, Clarissa (1); MOTA, Bruno (2); ARAÚJO, Lívia (3); BARBOSA, \\ George (4); ANDRADE, Fabíola (5)
}

(1) SIPPRO, clarissa.biotto@sippro.eng.br, (2) SIPPRO, bruno.mota@sippro.eng.br, (3) Construtora Colmeia, livia.araujo@colmeia.com.br, (4) Construtora Colmeia, george.barbosa@colmeia.com.br, (5) Construtora Colmeia, fabiola@colmeia.com.br

\begin{abstract}
RESUMO
O andon é uma ferramenta de gerenciamento visual utilizada em sistemas de produção para sinalizar o status das operações. Esta ferramenta é amplamente empregada na indústria manufatureira, porém, é pouco descrita na literatura acadêmica referente à indústria da construção, bem como sua utilização não é amplamente conhecida no setor. No entendimento das dificuldades inerentes por este tipo de produção, é necessário adaptar essa ferramenta aos canteiros de obras. Desta forma, um dispositivo andon foi implementado em um grande projeto de um resort horizontal, com mais de oitocentos apartamentos em 55 hectares, em Fortaleza (Ceará), com a intenção de indicar à equipe de engenharia quais são os problemas em cada estação de trabalho. O dispositivo foi adaptado em terminais touchscreen no interior de estações de trabalho que são compartilhadas por aproximadamente novecentos trabalhadores. Cada trabalhador possui um número próprio de identificação para acessar o terminal andon e indicar o local de trabalho e o status da operação que está executando. Como resultados, o andon permitiu a redução no número de paradas de atividades no canteiro por falta de insumos, os quais foram classificados em quatro categorias principais: material, mão de obra, projeto e segurança. Além disso, a ferramenta aumentou a transparência das operações, facilitando a detecção de problemas de logística e falhas nos planejamentos de médio e curto prazos. Alguns indicadores foram coletados, como tempo de parada média, tipo de profissional que mais aciona o andon, e os motivos das possíveis paralizações. Além disso, melhorou o senso de responsabilidade dos trabalhadores através da prevenção de problemas futuros que poderiam afetar a produção. Portanto, este artigo de cunho industrial descreve a implementação e o uso do andon adaptado a um projeto horizontal e serve de inspiração para outras empresas de construção para a implantação desta ferramenta em grandes canteiros de obras.
\end{abstract}

Palavras-chave: andon, construção enxuta, produção.

\begin{abstract}
The andon is a visual management tool used mainly in manufacturing systems to highlight the status of the operations. In construction industry, its use is not widely known nor reported in academic literature. In understanding the difficulties imposed by this kind of production, it is necessary to adapt this tool to the construction sites. An andon device was implemented in a 55 hectares area of large horizontal residential project, with more than eight hundred apartments, at Fortaleza, Brazil, in order to indicate for the engineer team the exactly position of the problem in each workstation. The device was adapted to a touch screen terminal inside the workstations and it was shared for nine hundred workers, each one has its own identification number. They have to log in at the andon terminal and indicate the actual status of the operation he is executing. As a result, the andon allowed increasing operations transparency, to identify some planning issues and to solve the main causes of interruptions that were classified in four main areas: lack of material, problems with manpower, design documentation and safety. Also, the andon improved worker's sense of responsibility by forecasting future problems that will affect the production. The use of the andon adapted to a horizontal project is an inspiration to other construction companies of how to implement this Toyota system traditional tool at extent construction sites.
\end{abstract}


Keywords: andon, information technology, lean construction, production control.

\section{INTRODUÇÃO}

Originado com o Sistema Toyota de Produção, o andon vem sendo amplamente utilizado em fábricas para melhorar a qualidade do produto (MAYNE et al., 2001; STROZNIAK, 2001; INMAN et al., 2003; TIERNEY, 2004 apud LI; BLUMENFELD, 2006). Entretanto, sua aplicação na construção civil ainda é escarça devido ao tipo especial de produção, que é diferente daquele encontrado na indústria manufatureira. De acordo com Bertelsen e Koskela (2004), a construção civil é, de fato, um tipo de produção conturbada, onde "são gerados produtos únicos diretamente no canteiro através da cooperação de equipes especializadas para as diversas tarefas a serem realizadas". Ballard e Howell (1998) também afirmam que a indústria da construção é caracterizada pelas condições construtivas do canteiro, unicidade do produto e organização temporária. Estas características prejudicam a adoção do andon nos canteiros de obra devido às dificuldades de instalar os dispositivos em cada posto de trabalho ou escritórios da obra.

Mesmo assim, como analisado por Kemmer (2006), há casos onde a aplicação dessa ferramenta foi bem sucedida em alguns edifícios altos (empreendimentos verticais), onde o sistema andon utiliza as instalações elétricas do prédio de forma a possibilitar os operários de solicitar ajuda e evitar a interrupção da atividade. Esta conhecida aplicação tecnológica torna-se onerosa para ser adaptada à construção de projetos residenciais horizontais, impostas às grandes distâncias a serem abrangidas e cabeadas.

Uma equipe de engenharia enfrentou o desafio de implementar um sistema andon em seu próprio canteiro de obras, que possui 99 blocos de apartamentos espalhados em mais de 55 hectares. Neste projeto, a administração da obra e os operários já vinham aplicando conceitos e ferramentas de construção enxuta, o que facilitou a implementação do andon e possibilitou o cumprimento dos pacotes de produção planejados pela equipe durante o plano de comprometimento semanal.

\section{$2 \quad A N D O N$}

O andon é a base para um dos principais pilares do Sistema Toyota de Produção - o jidoka, que significa "máquinas com inteligência humana". Ele é uma ferramenta de gestão de controle visual que mostra o status de uma operação em um determinado posto de trabalho. (LEI, 2008).

A ideia é proporcionar autonomia aos operários em mandar um alerta de ajuda para seus supervisores e parar o fluxo de produção quando há um problema em seus postos de trabalho (SHINGO, 1989; LIKER, 2004; LIKER; MEIER, 2006). O problema é comunicado imediatamente à equipe, e os líderes do grupo são os responsáveis por verificar onde exatamente o problema aconteceu (LIKER; MEIER, 2006). A ação mais importante é a solução para este problema (SHINGO, 1989). Ela constitui a base de uma cultura de parar a atividade para resolver o problema de forma a manter a qualidade desde o início (LIKER, 2004; LIKER; MEIER, 2006).

Em muitas empresas, ao tentar implementar um sistema andon, os operários geralmente encontram dificuldades em admitir que precisam de auxílio, e o uso se torna ineficaz caso se desenvolva atritos entre operários e líderes (LIKER; MEIER, 2006).

O sistema andon inclui um alarme sonoro e iluminação de alerta visual para indicar a localização do problema (LIKER; MEIER, 2006). Ele descreve o status real da 
produção, por exemplo; quantas máquinas estão em operação, uma anomalia como um problema de qualidade, ferramentas defeituosas, entre outros (LEI, 2008). Quando se implementa um andon, os problemas não podem mais ser escondidos, mas sim detectados e resolvidos (LI; BLUMENFILED, 2006).

\subsection{Andon na Indústria da Construção}

Em um edifício alto, o andon é utilizado em conjunto com cartões kanban e uma caixa heijunka. Cada posto de trabalho no edifício tem um painel andon composto por três interruptores: um verde, um amarelo e um vermelho (KEMMER et al., 2006; VALENTE, 2011). Esses interruptores acionam o díodo emissor de luz (LED) no painel de controle instalado no escritório da administração para que a equipe de engenharia possa visualizar o status da produção em cada estágio. O botão verde aciona o LED verde para indicar que as atividades estão decorrendo normalmente. $\mathrm{O}$ amarelo aciona $\mathrm{o}$ LED de mesma cor, indicando que uma atividade será interrompida nos próximos 30 minutos. Já o vermelho serve para indicar que a produção está completamente parada. Essa função é apresentada na Figura 1.

\section{Figura 1: equipamento andon e sua operação}

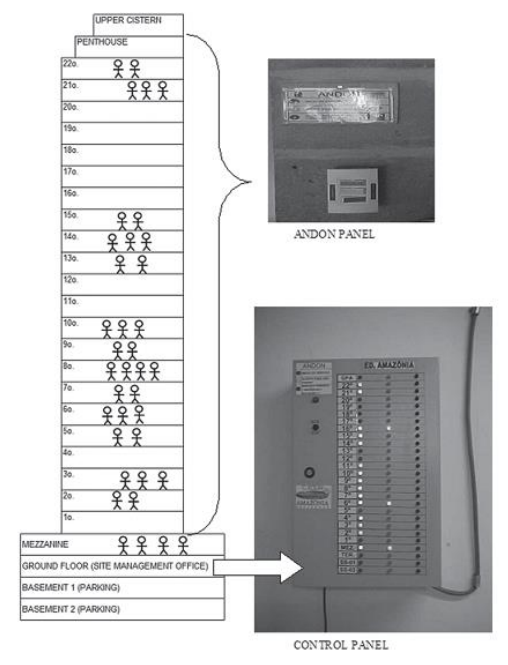

Fonte: Kemmer et al. (2006)

Toda manhã, quando as equipes chegam aos seus postos de trabalho, os operários acionam o botão verde no painel andon. Se eles estão cientes que vai faltar algum material, ferramenta, informação ou que algum detalhamento não se encontra nos projetos, ou que seu trabalho pode ser interrompido por algum motivo, um dos operários irá acionar o botão amarelo e esperar que o supervisor entre em contato por rádio para resolver o problema. Entretanto, caso a equipe interrompa seu trabalho, e o botão vermelho está pressionado, o supervisor entra em contato imediatamente com sua equipe no posto de trabalho e tenta solucionar o problema com a ajuda da equipe da administração (KEMMER et al., 2006; VALENTE, 2011).

As informações coletadas para controle dizem respeito às razões da interrupção das atividades, que podem ser devido a: treinamento de mão-de-obra, capacidade do sistema, planejamento e atraso do fornecedor. Todos esses motivos podem ser encontrados após a aplicação da técnica dos 5 Porquês (KEMMER et al., 2006). 
Em projetos com esse tipo de andon, as interrupções de atividade foram reduzidas significantemente. Também, aumentou-se a transparência, melhorando a comunicação entre a equipe de administração e os operários.

As maiores dificuldades em manter um sistema manual operando são: fazer com que os operários acionem os botões no painel andon de acordo com o status de suas atividades; fazer com que a administração grave os minutos que a produção esteve parada; seus motivos e qual equipe parou; e a comunicação necessária via rádio.

Também, é mais fácil usar o andon em um painel de controle LED quando o edifício já está com sua estrutura executada, pois após isso, os postos de trabalho ficam fisicamente definidos.

\section{DESCRIÇÃO DA EMPRESA CONSTRUTORA E DO PROJETO}

Este estudo de caso trata sobre a implementação de andon em uma construtora fundada em 1980 em Fortaleza, Ceará, Brasil, e atualmente com filiais em Campinas (São Paulo), Manaus (Amazonas) e Natal (Rio Grande do Norte). A empresa já entregou mais de 100 obras, incluindo edifícios comerciais e residenciais, flats e outros, todos nas áreas nobres das cidades, sempre primando por qualidade e conforto. A construtora não só tem um Programa de Qualidade Total desde 1998, mas também o certificado ISO 9001/2000 desde 2004, e começou a implementação de construção enxuta em suas obras e escritórios em 2013.

O projeto é um condomínio resort localizado na cidade de Aquiraz, Ceará, com uma área de 553.545,74 metros quadrados. O projeto começou em 2010 e tem prazo de conclusão em 10 anos. Durante esse período, será construída uma extensa área de lazer com piscinas, churrasqueira, campos de golfe, quadras esportivas e outros equipamentos, com 82 casas e 99 blocos de apartamentos, distribuídos em três tipos diferentes (A, B e C). A Figura 2 mostra as perspectivas do projeto.

\section{Figura 2: Planta do projeto e perspectiva de um bloco de apartamentos.}
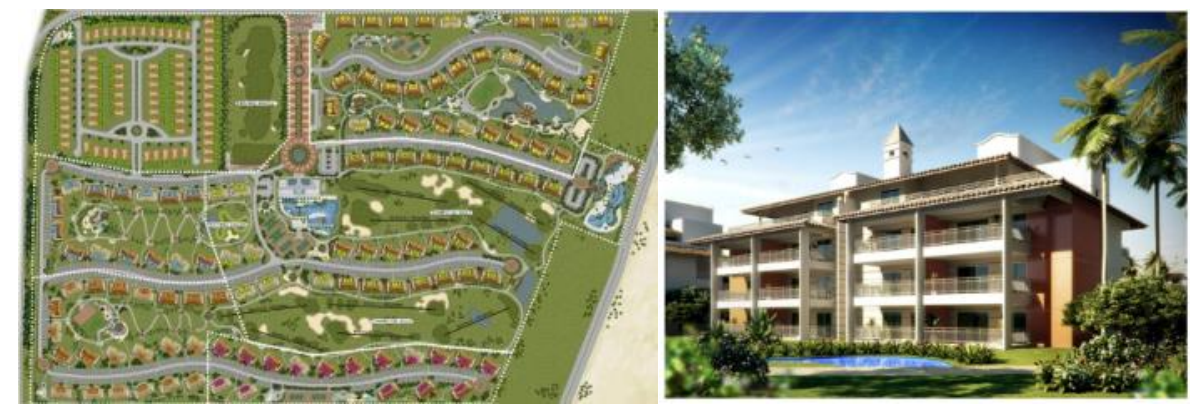

Fonte: Arquivos da Empresa

\subsection{Descrição das atividades}

O maior problema para implementar um sistema manual de andon nesta obra foi sua extensa área e o grande número de blocos de apartamentos e andares, com a dificuldade de instalar um painel andon em cada um. No total, seriam necessários 744 interruptores e mais de 100 quilômetros de cabeamento elétrico para conectar todos os postos de trabalho da obra ao painel de controle no escritório da administração.

Dessa maneira, a equipe de engenharia decidiu usar a tecnologia da informação para transferir os dados dentro da obra usando uma infraestrutura Wi-Fi já existente, 
procedente de um ano de implementação de construção enxuta neste projeto (Barbosa et al., 2013). Por conta disso, a implementação de andon é a continuidade de diferentes conceitos, ferramentas e técnicas de construção enxuta já implementadas. Assim, toda a linguagem de programação e infraestrutura mantiveram-se as mesmas. Portanto, a equipe de engenharia adicionou o andon no "Terminal Lean", onde os operários podem acionar o dispositivo sempre que necessário para que eles terminem suas tarefas.

As atividades de desenvolvimento do sistema andon comtemplaram as seguintes etapas:

1. Desenvolvimento do sistema: essa etapa incluiu as definições do escopo do sistema e suas adaptações para o extenso canteiro de obras. Ele foi programado em linguagem Delphi, usando o banco de dados SQL Server 2008 e um serviço web para enviar mensagens SMS para os celulares dos funcionários. Nesta etapa houve a compra do "Terminal Lean" touch screen. O sistema andon foi conectado ao principal software "Sistema Lean" através da conexão wireless do canteiro, o qual suporta o Planejamento e Controle da Produção (BARBOSA et al., 2013).

2. Teste e melhorias: durante 15 dias, o sistema andon foi testado em apenas um terminal, que era um bloco de apartamentos no canteiro. Nesta etapa, foi necessário treinar um operário para usar o andon e ele deveria compartilhar toda a informação com os outros no "Terminal Lean". Esta fase ocorreu do final de Setembro até o começo de Outubro de 2013.

3. Consolidação: após o período de testes, o sistema andon começou a operar em sua totalidade. O sistema foi avaliado e os resultados foram medidos de acordo com alguns indicadores com dados de Outubro de 2013 até Fevereiro de 2014.

\section{DESENVOLVIMENTO}

\subsection{O sistema de andon}

Foram instalados três "Terminais Lean" espalhados pelas principais vias do canteiro de obras. Eles ficam no nível térreo dos blocos de apartamentos (blocos 18, 42 e 71) e suas localizações estão indicadas por placas na obra (Figura 3). O andon deve ser ativado através do "Terminal Lean", que contém outros sistemas utilizados pelos funcionários.

\section{Figura 3: Localização e placas dos "Terminais Lean" no canteiro de obra onde os}

\section{operários podem acessar o dispositivo andon}
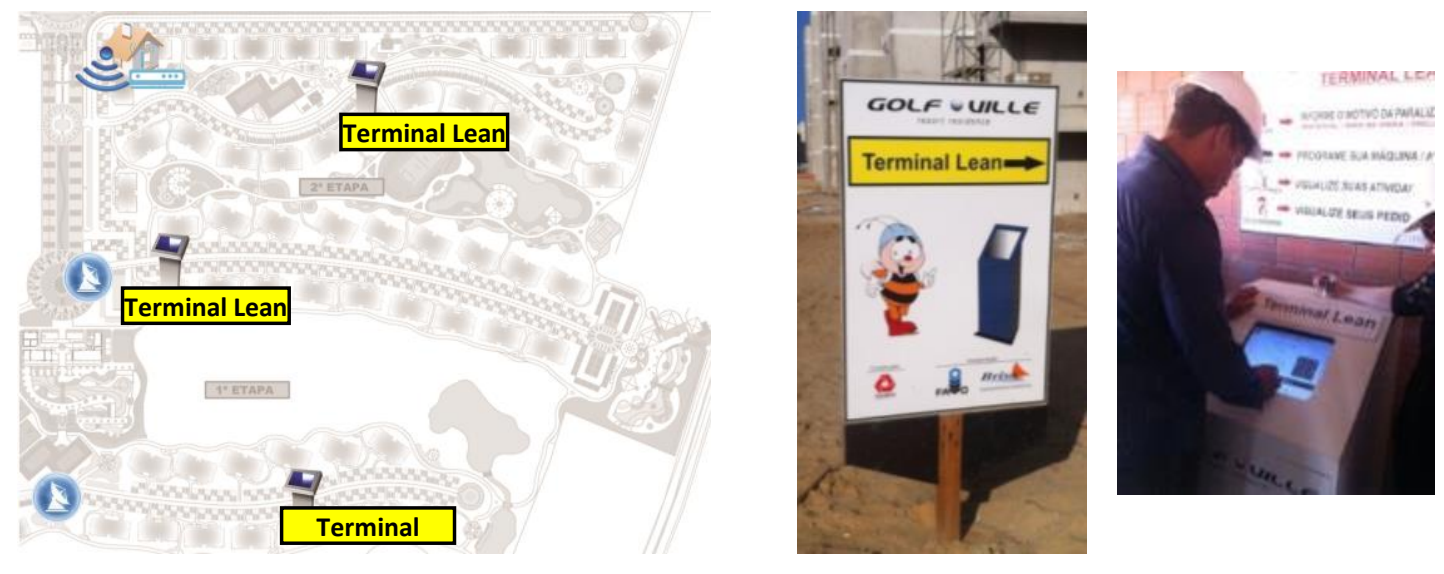
$\mathrm{O}$ acionamento pode ser feito por qualquer operário, mantendo o princípio de adotar o andon para os operários da linha de frente. Se um deles quer sinalizar que sua equipe irá parar a produção, ele precisa fazer o login no sistema, escolher a tela do andon, informar seu posto de trabalho, o motivo pelo qual eles irão parar e confirmar seu acionamento. Foram escolhidas quatro categorias de parada de atividade: material, mãode-obra, projeto e segurança. Então, a equipe de engenharia recebe um alerta na tela do escritório da administração e eles têm até 10 minutos para solucionar os problemas relacionados à segurança e 30 minutos para as demais categorias antes que a produção pare.

$\mathrm{O}$ assistente da administração identifica as atividades que podem ser interrompidas e suas causas. Ele é responsável por solucionar os problemas de suprimento na obra. A maior parte dos problemas de andon é fácil de resolver, e os engenheiros não são notificados.

O passo a passo do procedimento para acionar o andon no "Terminal Lean" é mostrado na Figura 4.

Figura 4: Passo-a-passo de como um operário pode ativar o dispositivo andon.
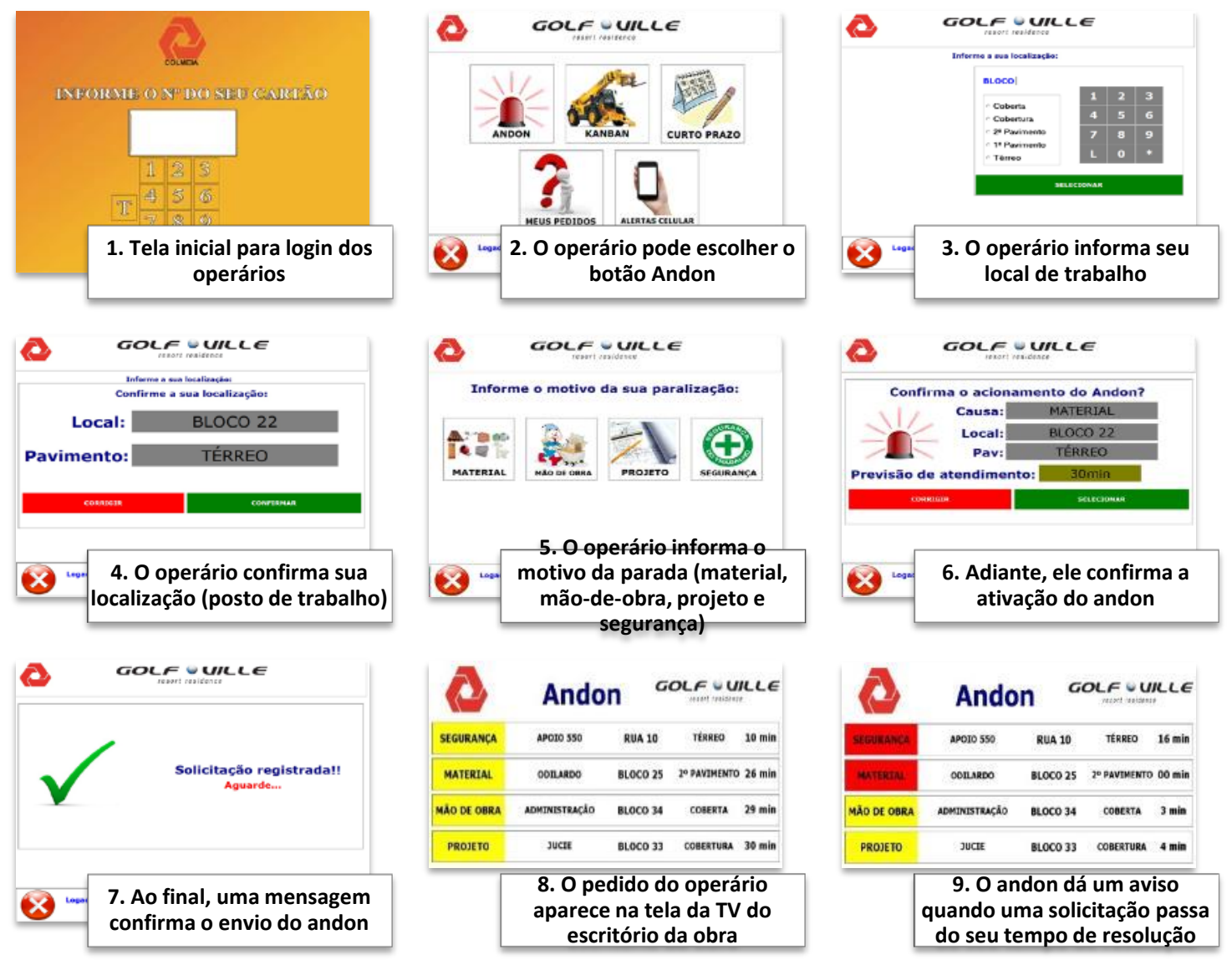

\section{RESULTADOS DO SISTEMA DE $A N D O N$}

\subsection{Estatísticas}

Alguns indicadores do andon podem ser facilmente produzidos devido à coleta automática de dados no banco de dados do sistema. Todos os dados foram obtidos durante um período de cinco meses, de Outubro de 2013 a Fevereiro de 2014. O total de 
acionamentos do andon até agora foi de 187 vezes. Este total é dividido em mão-deobra, material, projeto e problemas de segurança, conforme mostrado no gráfico da Figura 5. Pode ser visto que o quesito "material" é o maior motivo para o acionamento do andon pelos operários, representando $82 \%$.

A distribuição do acionamento do andon durante os meses também pode ser vista na Figura 6, que mostra o forte uso desta ferramenta nos primeiros dois meses de sua implementação, 62 acionamentos entre Outubro e Novembro de 2013. Nos meses seguintes, este número diminuiu consecutivamente, provavelmente porque os engenheiros aprenderam como programar os recursos para seu plano de comprometimento, ou os operários foram utilizando intensivamente os cartões kanban para solicitar recursos.

\section{Figura 5: Acionamento do andon por categoria e por mês}

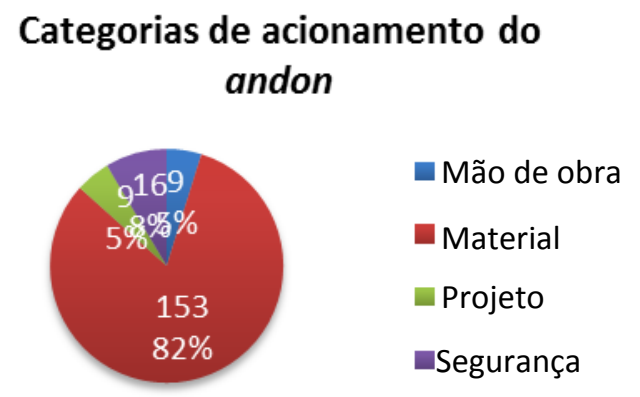

\section{Acionamento do andon por mês}

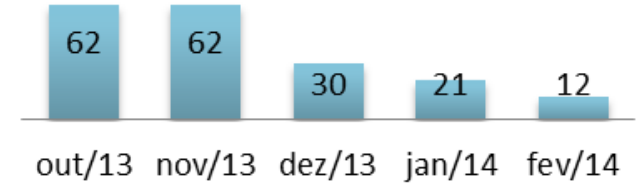

Outro indicador foi o acionamento do andon para encontrar o desvio de programação. Durante 5 meses, $92 \%$ de todos os acionamentos do andon foi para solicitar algum recurso para o mesmo posto de trabalho e atividade que foi planejada no plano de comprometimento. O gráfico da Figura 6 mostra que $8 \%$ de todo acionamento do andon foi para atividades com desvio de programação ou informais, que não estavam programadas para acontecer.

Figura 6: Acionamento do andon com desvio de programação

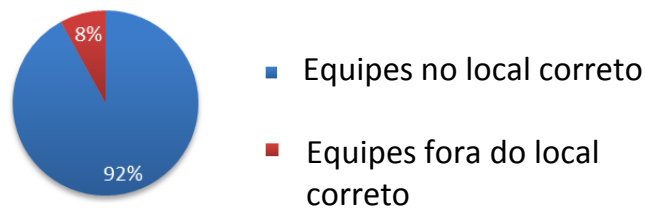

A eficiência da equipe de engenharia em resolver os problemas antes da interrupção da atividade foi avaliada (Figura 7). Foi possível verificar que a categoria "segurança" foi a mais difícil de resolver em poucos minutos. Apenas 59\% de todas as atividades no sistema andon foram resolvidas antes de sua parada.

Figura 7: Percentual de atividades solucionadas antes e depois de interrompidas

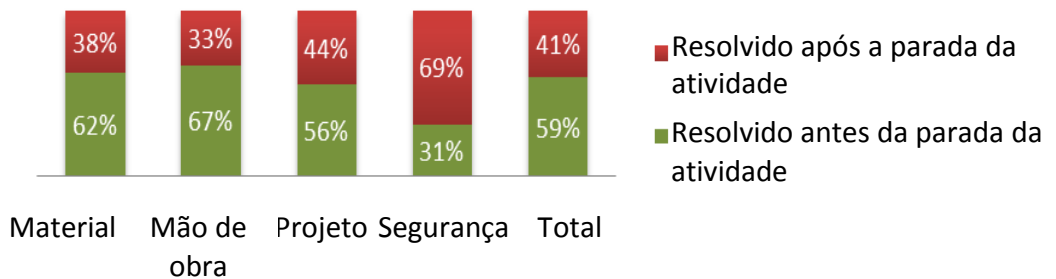


De todos os acionamentos do andon, foi possível analisar a média de tempo de desativação para as quatro categorias. A categoria "material" é a que consome mais tempo para desligar o andon: 37 minutos é a media para desativá-lo, ou seja, para solucionar o problema; 48 minutos é a média para atividades que pararam, ou seja, excederam os 30 minutos para serem resolvidas; e 11 minutos foi a média para as atividades que foram solucionadas antes de sua parada, ou seja, antes dos 30 minutos (Figura 8).

Figura 8: tempo médio de desativação do andon (em minutos)

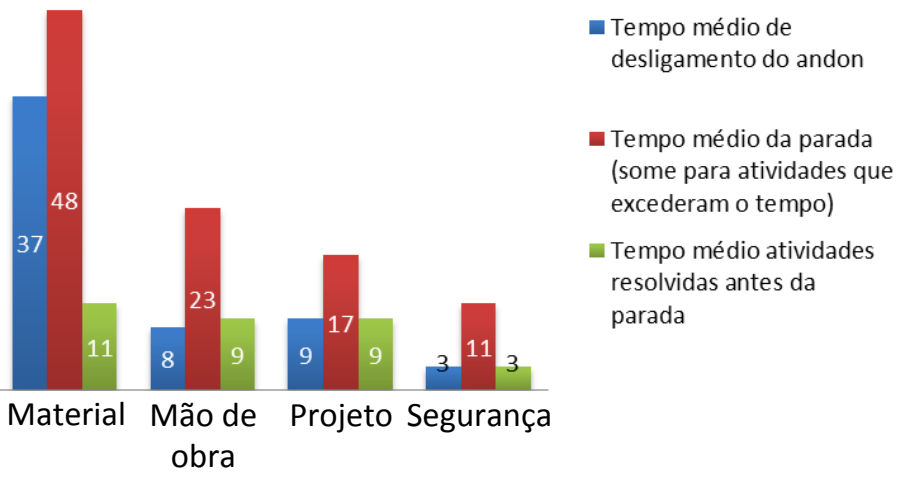

Os próximos indicadores se referem à mão de mão-de-obra (Figura 9). O primeiro indica que apenas $3 \%$ de todos os acionamentos do andon foi feito por mão-de-obra terceirizada, enquanto $97 \%$ foi oriundo de mão-de-obra própria. Os motivos podem ser devido ao bom planejamento pela empresa terceirizada, ou, caso tenha havido falta de algum recurso, apenas a empresa terceirizada poderia resolver o problema de sua mãode-obra, e o acionamento do andon não tenha sido necessário.

No segundo gráfico é possível verificar que o profissional que mais utilizou o andon foi o pedreiro, $48 \%$, seguido pelo servente, $31 \%$.

Figura 9: ativação do andon por tipo de profissional e por função do operário
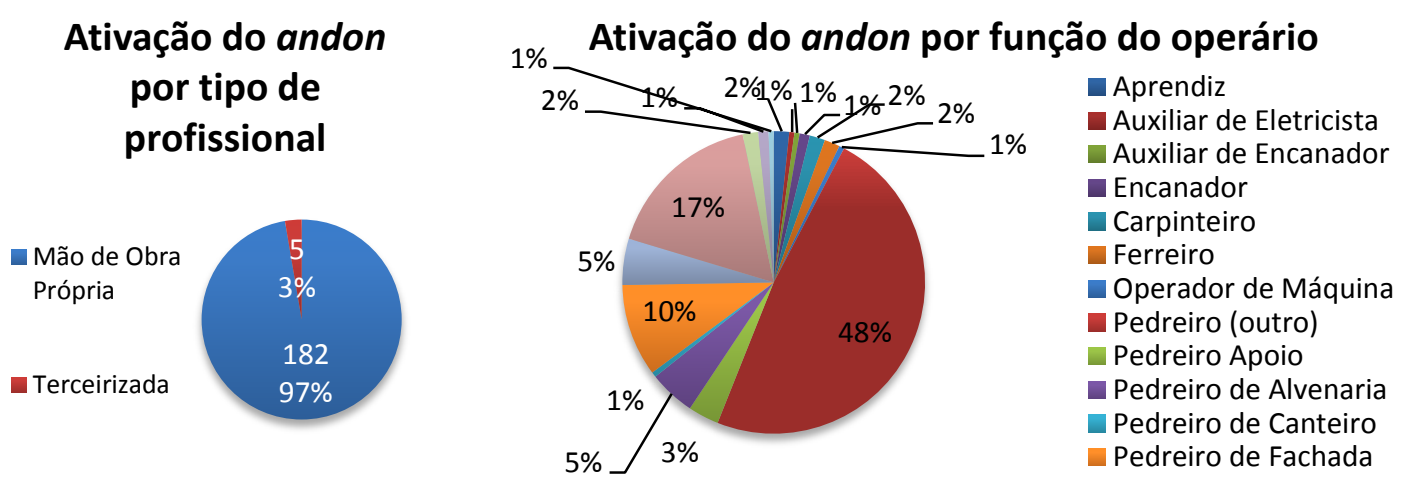

Assim que um operário aciona o andon, é possível saber sua localização dentro do canteiro de obras. O próximo gráfico (Figura 10) trata do acionamento do andon por blocos de apartamentos e outras edificações na área comum do projeto. O local com mais acionamento do andon é o bloco 70. Neste bloco fica instalado o "Terminal Lean", entretanto são necessários mais dados para afirmar que a localização do andon no canteiro influencia seu acionamento. 
Figura 10: localização dos acionamentos do andon



\subsection{Melhorias percebidas}

Como se trata de um sistema informatizado, a coleta de dados é automática. Quando o andon é acionado, um alerta surge em uma tela no escritório da engenharia com uma contagem regressiva para resolver o problema. Deste momento em diante, todos os dados são registrados no sistema, o que melhorou a velocidade de comunicação e a transparência das atividades com problemas para toda a equipe de engenharia.

Neste sistema andon, o operário é responsável por informar o porquê de ele estar interrompendo a atividade. Isto resultou em uma queda no tempo de resolução de um problema, já que o engenheiro não mais precisa procurar a equipe apenas para perguntala o motivo da parada.

Como o operário precisa registrar sua localização na obra, o sistema andon confere automaticamente onde ele deveria estar de acordo com o plano de comprometimento e onde ele realmente se encontra. Assim, é possível detectar desvios de programação que justifiquem a falta de recursos para realizar uma atividade não programada. Então, também é possível encontrar as atividades informais que podem gerar perdas por making-do.

Dados relacionados à redução de custos, tais como tempo de parada, estão sendo coletados de forma que os autores possam analisar a eficiência da ferramenta.

Os principais benefícios que o sistema andon possibilitou foram a resolução dos problemas e a melhoria da qualidade do plano de comprometimento pela equipe de engenharia. Também, um recurso bastante caro como mão-de-obra deixa de se tornar ocioso devido a problemas de suprimentos e as perdas de making-do podem ser reduzidas.

\subsection{Dificuldades durante a implementação}

As dificuldades encontradas na implementação do andon no canteiro estão relacionados ao envolvimento dos funcionários. Treinamentos devem ser sempre realizados para atualizá-los e para que eles entendam a importância de notificar a equipe de engenharia quando a produção está perto de parar ou já está parada. O oposto também aconteceu no inicio da implementação, quando alguns operários acionaram o andon sem terem feito suas solicitações através do kanban.

Uma limitação desse sistema andon é não ser possível acionar o andon para sinalizar a situação "verde" da produção: os operários estão trabalhando no local certo com todos os recursos necessários. Atualmente, o andon apenas indica as situações "amarelo" e 
"vermelho" da produção, e este é o motivo pelo qual a equipe de engenharia não sabe se os operários estão no local certo de trabalho conforme programado.

\section{CONCLUSÕES}

O sistema andon tem diversos benefícios ao gerir os suprimentos dos blocos em construção no canteiro de obras. A transparência da informação resultou em melhorias ao plano de comprometimento e na diminuição de paradas na produção.

O sistema andon ainda encontra problemas quanto ao comprometimento do operário em acionar o dispositivo e em obter o status real da produção. Todavia, ele foi uma adaptação dos conceitos de andon para um canteiro de obras de grande porte que deu apoio ao kaizen para o planejamento e controle da produção.

\section{AGRADECIMENTOS}

Os autores agradecem os diretores da Construtora Colmeia pela oportunidade de desenvolvimento do trabalho, aos colaboradores do empreendimento Golf Ville pela vontade e esforço nas implementações lean e aos consultores da SIPPRO pela parceria.

\section{REFERÊNCIAS}

BARBOSA, G., ANDRADE, F., BIOTTO, C., MOTA, B. Implementing lean construction effectively in a year in a construction project. Proceedings for the 21st Annual Conference of the International Group for Lean Construction, Fortaleza, Brazil, 1017-1026. 2013

BERTELSEN, SVEN; KOSKELA, LAURI. Construction beyond lean: a new understanding of construction management. Proceedings for the 12th Annual Conference of the International Group for Lean Construction, Elsinore, Denmark, 1-11. 2004

KEMMER, S.L., SARAIVA, M.A., HEINECK, L.F.M., PACHECO, A.V.L., NOVAES, M.V., MOURÃO, C.A.M.A. AND MOREIRA, L.C.R.. The use of andon in high rise Building. Proceedings for the 14th Annual Conference of the International Group for Lean Construction, Santiago, Chile, 575-582. 2006

BALLARD, G. AND HOWELL, G.. What kind of production is construction?" Proceedings for the 6th Annual Conference of the International Group for Lean Construction, Guarujá, Brazil. 1998

LEAN ENTERPRISE INSTITUTE. Lean Lexicon: a graphical glossary for Lean Thinkers. The Lean Enterprise Institute, Cambrigde, 126pp. 2008

LI, JINGSHAN AND BLUMENFELD, DENNIS E.. Quantitative analysis of a transfer production line with Andon. IIE Transactions, 38 (4) 837-846. 2006

LIKER, J.K.. The Toyota Way: 14 Management Principles from the World's Greatest Manufacturer, McGraw-Hill, New York, NY. 2004

LIKER, JEFFREY K. AND MEIER, DAVID. The Toyota Way Fieldbook: A Practical Guide for Implementing Toyota's 4Ps. Mcgraw-Hill, New York, 498 pp. 2006

SHINGO, SHIGEO. A Study of the Toyota Production System from an Industrial Engineering Viewpoint. Productivity Press, Cambridge, 257pp. 1989

VALENTE, CAROLINE PORTO. Acompanhamento e avaliação lean em um canteiro de obras: uma proposta de auditorias lean. Monografia (graduação) - Universidade Federal do Ceará, Departamento de Engenharia Estrutural e Construção Civil, Curso de Engenharia Civil, Fortaleza, 64pp. 2011 